\title{
Lack of correlation between delayed traumatic intracerebral haematoma and disseminated intravascular coagulation
}

\author{
YUSUKE SAWADA, DAIKAI SADAMITSU, TOSHIHISA SAKAMOTO, \\ KATSUMI IKEMURA, TOSHIHARU YOSHIOKA, TSUYOSHI SUGIMOTO
}

From the Department of Traumatology Osaka University, School of Medicine, Japan

SUMMARY The relationship between delayed traumatic intracerebral haematoma and disseminated intravascular coagulation was investigated. Eighteen patients with delayed traumatic intracerebral haematoma were selected as the study subjects from 268 consecutive patients with head trauma and compared with another two groups of patients with closed head injury (20 cases) and with multiple injuries ( 24 cases). All cases had six laboratory studies for disseminated intravascular coagulation for 7 days. The results revealed no different clotting abnormalities among the three groups. From the laboratory point of view, it could be concluded there was no essential relationship between disseminated intravascular coagulation and the appearance of delayed traumatic intracerebral haematoma.

With development of serial computed tomography (CT) for patients with acute severe head injuries, many reports have been published of delayed traumatic intracerebral haematoma. In several case reports and series, a relationship between delayed traumatic intracerebral haematoma and disseminated intravascular coagulation was noted. In this report, we found that there was no essential relationship between disseminated intravascular coagulation and delayed traumatic intracerebral haematoma.

\section{Materials and methods}

Eighteen cases of delayed traumatic intracerebral haematoma were selected from 268 consecutive patients with head trauma treated at our department during the period from March 1980 to October 1982. Delayed traumatic intracerebral haematoma patients (Group one) had a Glasgow Coma Score of 10 or less. As controls, 20 consecutive patients with closed head injuries having no other injuries (Group two) were included. In addition, 24

Address for reprint requests: Dr Yusuke Sawada, MD, 1-1-50, Fukushima, Fukushima-ku, Osaka, 553, Japan.

Received 16 September 1983 and in final revised form 3 April 1984. Accepted 5 April 1984 patients with more fractures than of one humerus (Group three) who were comparable to patients of Group one as regards Glasgow Coma Score and period of admission were also studied. Initial CT was performed in all patients of the three groups (62 in a total) on admission which occurred within two hours after trauma.

All patients had laboratory studies for disseminated intravascular coagulation each day until the seventh hospital day. The parameters studied included platelet count, prothrombin time, active partial thromboplastin time, serum fibrinogen, fibrin degradation products and protamine sulphate test.

Delayed traumatic intracerebral haematoma was diagnosed, if the initial CT scan revealed no lesion, no low density area or "salt \& pepper" lesion, but when paranchymal high-density lesions were revealed on repeated study made 8 hours after the initial scan. The interval between the initial CT scan and the time when the scan demonstrating delayed traumatic intracerebral haematoma was obtained was 48 hours or less in 13 patients. Haematoma was detected in three patients within 24 hours, in 10 within 48 hours, and in five at 13 days after injury.

\section{Results}

(1) Fibrinogen: In all patients severe hypofibrinogaemia was observed during the 24 hours after trauma, but recovery to normal occurred 

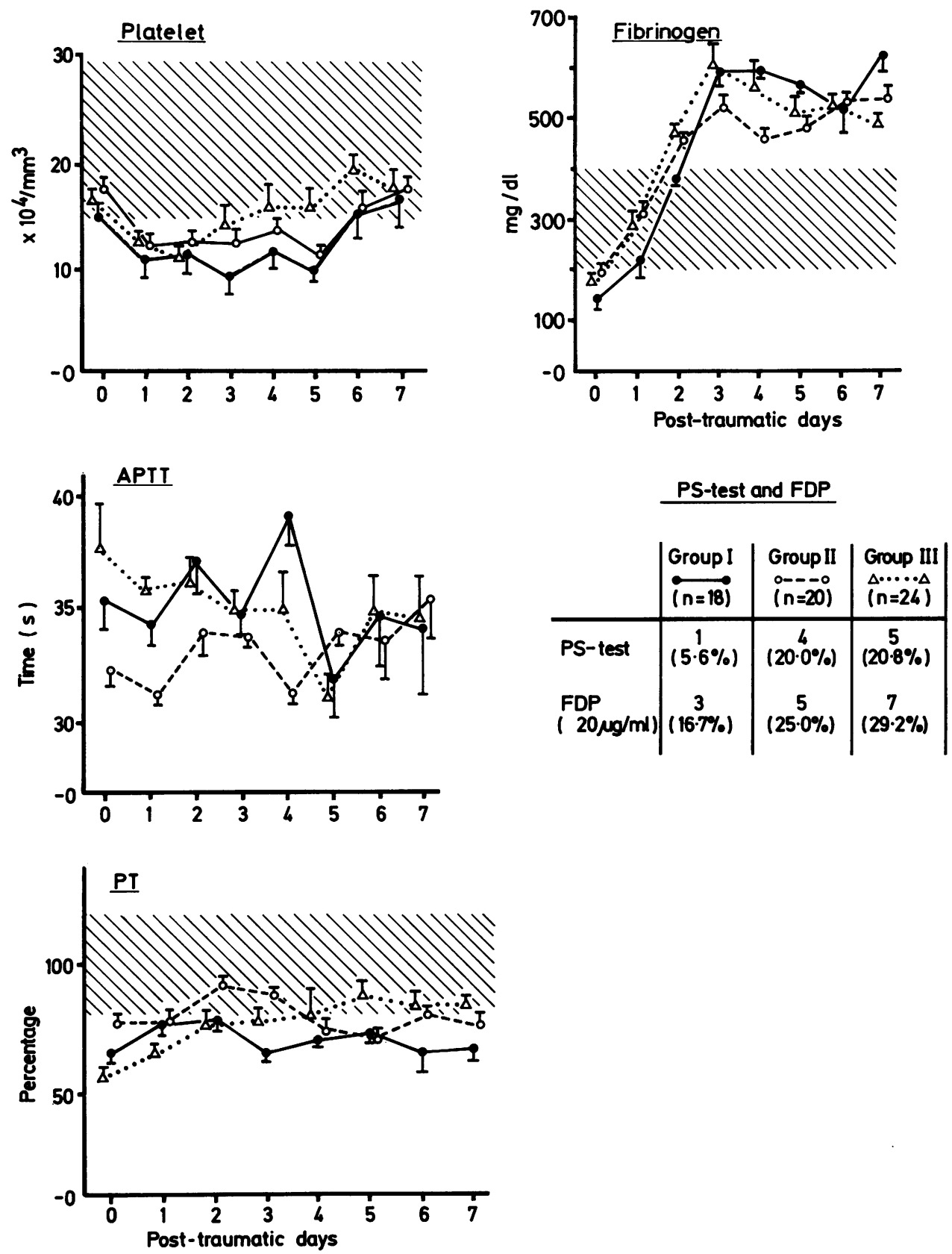

Fig Changes of six laboratory studies of three groups for 7 days. 
abruptly within the next 24 hours. Hyperfibrinogaemia persisted at least for 7 days. No statistical difference was found between the three groups.

(2) Platelet count: In all three groups, the platelet count was almost normal on admission, decreasing promptly within 24 hours. During the following 4 days, abnormal levels were observed. It was as low as under $10 \times 10^{4} / \mathrm{mm}^{3}$ in 10 cases in Group one, in eight cases in Group two and in nine cases in Group three. No statistically significant differences were seen between any of the three groups.

(3) Prothrombin time: This showed low or borderline levels throughout the study period in all three groups, without significant differences.

(4) Active partial thromboplastin time was variable especially in the early period after injury. When compared with the normal levels in our laboratory, which ranged from 25 to 45 seconds, there were no patients with definitely abnormal active partial thromboplastin times.

(5) Fibrin degradation products and protamine sulphate test: The number and percentage of patients who gave positive results for the protamine sulphate test and who showed serum levels of fibrin degradation products exceeding $20 \mu \mathrm{g} / \mathrm{ml}$ are shown in the figure. No differences among the groups were seen.

\section{Discussion}

One of the most common aetiological mechanisms suggested for delayed traumatic intracerebral haematoma is disseminated intravascular coagulation following destructive brain damage. ${ }^{1}$ Disseminated intravascular coagulation in traumatised patients is probably due to the combination of acute hypoxic hypotension, acidosis and release of appreciable amounts of tissue thromboplastin from damaged organs and other tissues. ${ }^{2}$ As is well known, the brain is a potent source of tissue thromboplastin and therefore many case reports and series have suggested disseminated intravascular coagulation as a fatal complication after severe head injury. ${ }^{3-s}$

Patients with acute disseminated intravascular coagulation associated with sepsis or after delivery are rare. Although their usual symptoms are due to bleeding or a tendency to bleed, such symptoms were not seen in our series. Moreover, we found nothing remarkable in the laboratory findings of patients in this series who had delayed traumatic intracerebral haematoma. As disseminated intravascular coagulation is a systemic disease, we do not agree with the notion that it develops only in a localised intracranial region with no other associated clinical signs.

In this series, we could not identify the cause of delayed traumatic intracerebral haematoma, but we concluded that there is no essential relationship between systemic disseminated intravascular coagulation and the appearance of delayed traumatic intracerebral haematoma.

\section{References}

${ }^{1}$ Astrup T. Assay and content of tissue thromboplastin in different organs. Thromb Diath Haemorrh $1965 ; 14: 401-16$.

${ }^{2}$ Bell WR. Disseminated intravascular coagulation. Johns Hopkins Med J 1980;146:289-99.

${ }^{3}$ Pondaag W. Disseminated intravascular coagulation in head injured patients. Adv Neurosurg 1978;6:159-63.

${ }^{4}$ Stinchini A, Baudo F, Nosari AM, Panzacchi G, De Cataldo F. Defibrination and head injury. Lancet 1974;ii:957.

5 Van der Sande JJ, Veltkamp JJ, Boekhout-Mussert RJ, Bouwhuis-Hoogerwerf ML. Head injury and coagulation disorders. J Neurosurg 1978;49:357-65. 